\title{
Development of a Bottom-Hole Gamma-Ray Diagnostic Capability for High-Level Environments, During CTBT On-Site Inspection Drilling
}

\author{
Robert Fontenot \\ Syed Shakir \\ Schlumberger-Anadrill, Sugarland, TX \\ Francois Heuze \\ Michael Butler \\ Lawrence Livermore National Laboratory, Livermore, CA
}

This report was prepared for the U.S. Department of Energy's Division of Nonproliferation and National Security May 1998

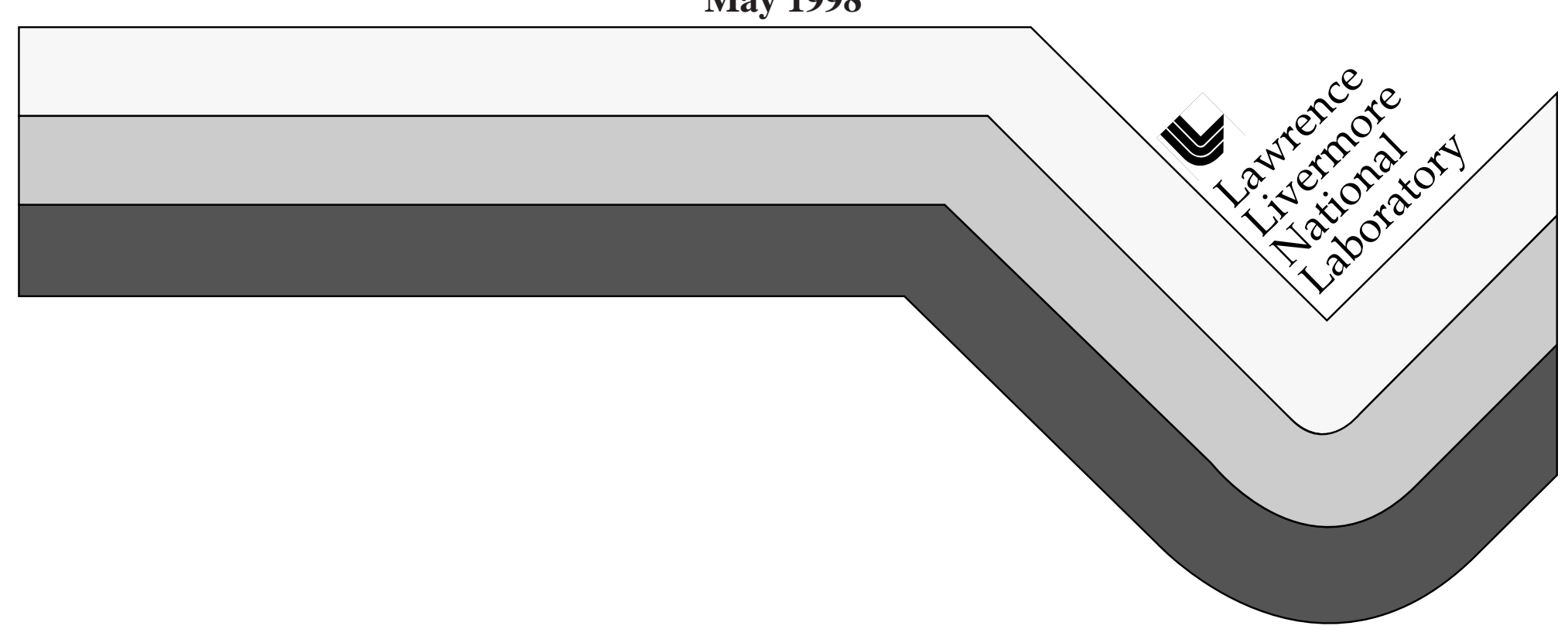




\section{DISCLAIMER}

This document was prepared as an account of work sponsored by an agency of the United States Government. Neither the United States Government nor the University of California nor any of their employees, makes any warranty, express or implied, or assumes any legal liability or responsibility for the accuracy, completeness, or usefulness of any information, apparatus, product, or process disclosed, or represents that its use would not infringe privately owned rights. Reference herein to any specific commercial product, process, or service by trade name, trademark, manufacturer, or otherwise, does not necessarily constitute or imply its endorsement, recommendation, or favoring by the United States Government or the University of California. The views and opinions of authors expressed herein do not necessarily state or reflect those of the United States Government or the University of California, and shall not be used for advertising or product endorsement purposes.

Work performed under the auspices of the U.S. Department of Energy by Lawrence Livermore National Laboratory under Contract W-7405-ENG-48. 


\section{TABLE OF CONTENTS}

Page

1. BACKGROUND AND OBJECTIVE ….............................

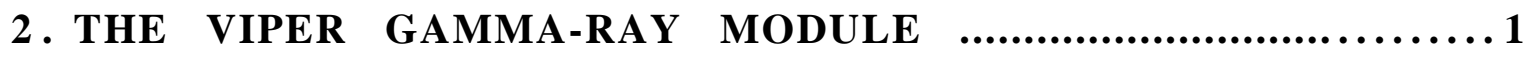

3. MODIFICATIONS TO THE GAMMA-RAY MODULE .................2

4. CALIBRATION TESTING $\quad$..........................................

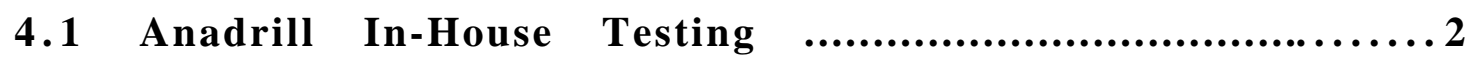

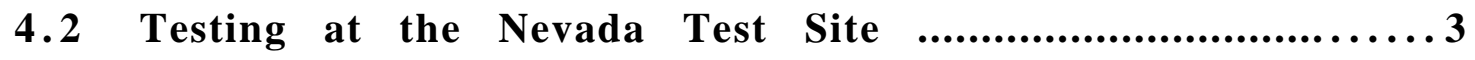

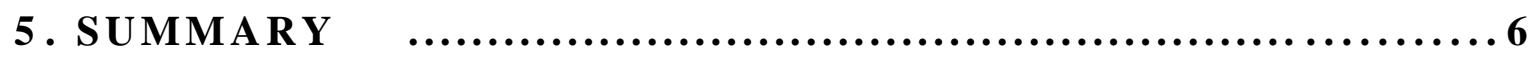

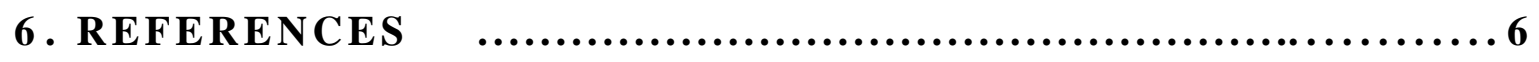

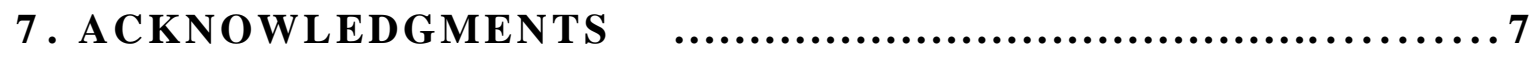





\section{BACKGROUND AND OBJECTIVE}

The verification regime of the Comprehensive Test Ban Treaty (CTBT) provides for the possibility of on-site inspections (OSI's) to resolve questions concerning suspicious events which may have been clandestine nuclear tests. The initial phase of an OSI may provide enough evidence to justify a request to the CTBT Organization for allowing drilling, so as to recover further evidence of a nuclear event.

The equipment that was used for such "re-entry" drilling in the days of U.S. underground nuclear testing is considered too heavy and cumbersome for OSI deployments. So, an effort was initiated in 1995 to define, assemble, and demonstrate a new OSI drilling capability. Coiled-tubing (C-T) was selected as the most attractive technology because of its portability and its directional drilling capability (1). Following this selection, a preliminary engineering design was performed in 1996 for a Rapid Deployment Drilling System (RDDS). This system must have capabilities for downhole diagnostics of temperature and gamma-rays, since both types of data could be used to confirm the presence of an underground nuclear explosion. The study then identified two candidate downhole diagnostic systems operating with CT: the VIPER system of Schlumberger-Anadrill, and the Transocean system (2).

In the current phase of this continuing effort the VIPER system has been retained as the first candidate because, everything else being equal, it is readily accessible domestically. One project, conducted by Maurer Engineering of Houston, TX, is specifying the details of the proposed CT system, its footprint, its modalities of air transport, and its costs of deployment and operation. The expected rate-of-penetration in rocks with unconfined compressive strength up to 14,500 psi (100 $\mathrm{MPa}$ ) is also being estimated, based on laboratory-scale drilling tests on rock cores.

Another project, which is the object of this report, has for an objective to develop and calibrate a downhole gamma-ray diagnostic capable of operating in the expected high-intensity environment near an underground nuclear cavity. The commercially available Anadrill VIPER logging assembly is calibrated to operate at levels of 0 to 250 American Petroleum Institute (API) units. These levels are much smaller than those necessary to confirm a clandestine nuclear explosion.

The scope of the project is to make the necessary modifications to the VIPER gamma-ray module to meet minimum detection requirements of 50,000 API. At such a level, which is more than two orders of magnitude higher than seen in natural formations, the origin of gamma-rays could only be from underground nuclear test products.

\section{THE VIPER GAMMA-RAY MODULE}

The gamma-ray detector used in VIPER is a NaI crystal and photomultiplier tube (PMT) assembly. When gamma-rays (natural or otherwise) hit the NaI crystal it emits a small quantity of light. This light is converted to an electrical charge and amplified many times within the PMT. The end result is a small electrical pulse from each gamma-ray particle that hits the crystal. These pulses are continuously counted to give an output in counts per second (cps). This count is then converted to API, a measurement system developed by the American Petroleum Institute. Conversion from cps to API is affected by crystal size, shielding material around the detector, and many other variables in the drilling process. VIPER has an average conversion factor of 0.8 . The normal operating range of the VIPER detector in standard practice is zero to 250 API units $(\sim 312 \mathrm{cps})$.

The gamma-ray module is comprised of the detector and the electronics package. The two electronic boards supply the high voltage necessary for operation of the PMT. They also filter and 
record the data coming from the sensor. These data are then sent on to the main tool processor for transmission to the surface. The entire gamma-ray detector is specially packaged to handle the severe environments seen in drilling wells. The package can handle temperatures up to $302^{\circ} \mathrm{F}$ $\left(150^{\circ} \mathrm{C}\right)$, and pressures up to $18,000 \mathrm{psi}(124 \mathrm{MPa})$. It also can handle the small radius curves often desired in C-T drilling.

\section{MODIFICATIONS TO THE GAMMA-RAY MODULE}

After completing several in house tests, it was concluded that no hardware modifications were needed to meet the specifications for the higher detection levels. However, modifications to three different software packages were required.

The software in the gamma-ray module was changed to handle the higher frequency of data. Modifications were also made to have the module transmit a special word identifying itself as the "high rate" gamma-ray module. The main CPU software in VIPER was modified to be able to toggle between normal mode and "high-rate", after identifying the special data word. This allows the tool to operate with either the normal or high-rate gamma-ray software. These modifications have been implemented into the standard release of this software.

The final modifications were made to the surface software to determine if the normal or "high-rate" data are being received. Once determination has been made, the data can be handled and stored properly. These modifications have also been implemented into the standard release of this software.

\section{CALIBRATION TESTING}

Two separate tests were conducted with the gamma-ray detector and new software. The first test was completed in house, at Anadrill, with only Anadrill personnel involved. This test confirmed the full operation of the system prior to the second test at the Nevada Test Site (NTS), with Lawrence Livermore National Laboratory (LLNL) personnel. Both tests are detailed here.

\subsection{Anadrill in house testing}

Tests were done to determine if the electronics, software, and gamma-ray detector can discriminate up to 65,000 cps. The test was broken down into two stages. The first part determined if the electronics and software alone could handle the high count rates. The second part determined if the count rates could be handled by the entire data system.

\section{Test Specifications}

The gamma-ray detector provides voltage pulses proportional to the energy of the incident gamma radiation. The first phase of testing was with the gamma-ray detection electronics and the modified software, combined with a function generator to simulate the voltage pulses. A frequency sweep from $100 \mathrm{~Hz}$ to $65 \mathrm{kHz}$ was performed to verify the electronics function and the modified software.

The second phase of testing was performed on the entire gamma-ray module. The test verified the performance of the gamma-ray sensor up to the specified cps levels. Background counts were taken before and after the test to ensure good quality of the measurement. A Cesium-137 (1.7 Curie) source was used to excite the crystal up to the specified levels. Testing was done in a nuclear laboratory located in the Anadrill facility. 


\section{Results}

During the first test, the modified software functioned as expected throughout the frequency range from $100 \mathrm{~Hz}$ to $65 \mathrm{kHz}$. At the higher end of the frequency range detected counts were off by $0.1 \%$.

During the second test, the background counts in the lab were approximately $70 \mathrm{cps}$. When the source was removed from the holding pit the background count increased to $450 \mathrm{cps}$. As the module was moved closer to the source, the counts continued to rise. When the distance was decreased to 6 in $(15 \mathrm{~cm})$, the counts hit its maximum of $65,000 \mathrm{cps}$. The counts returned to the background reading of $450 \mathrm{cps}$ as the source was moved away from the module, and eventually back down to $70 \mathrm{cps}$ when the source was stored in the pit. No secondary detector was used during this test.

\section{Conclusions}

The software functioned as expected with and without the detector. Both tests were completed successfully. The module was ready for further testing with a source other than Cesium-137.

\subsection{Test at the Nevada Test Site}

The confirmation calibration of the new VIPER gamma-ray module was performed at LLNL's building 600 at NTS. The tested system is shown in Figure 1.

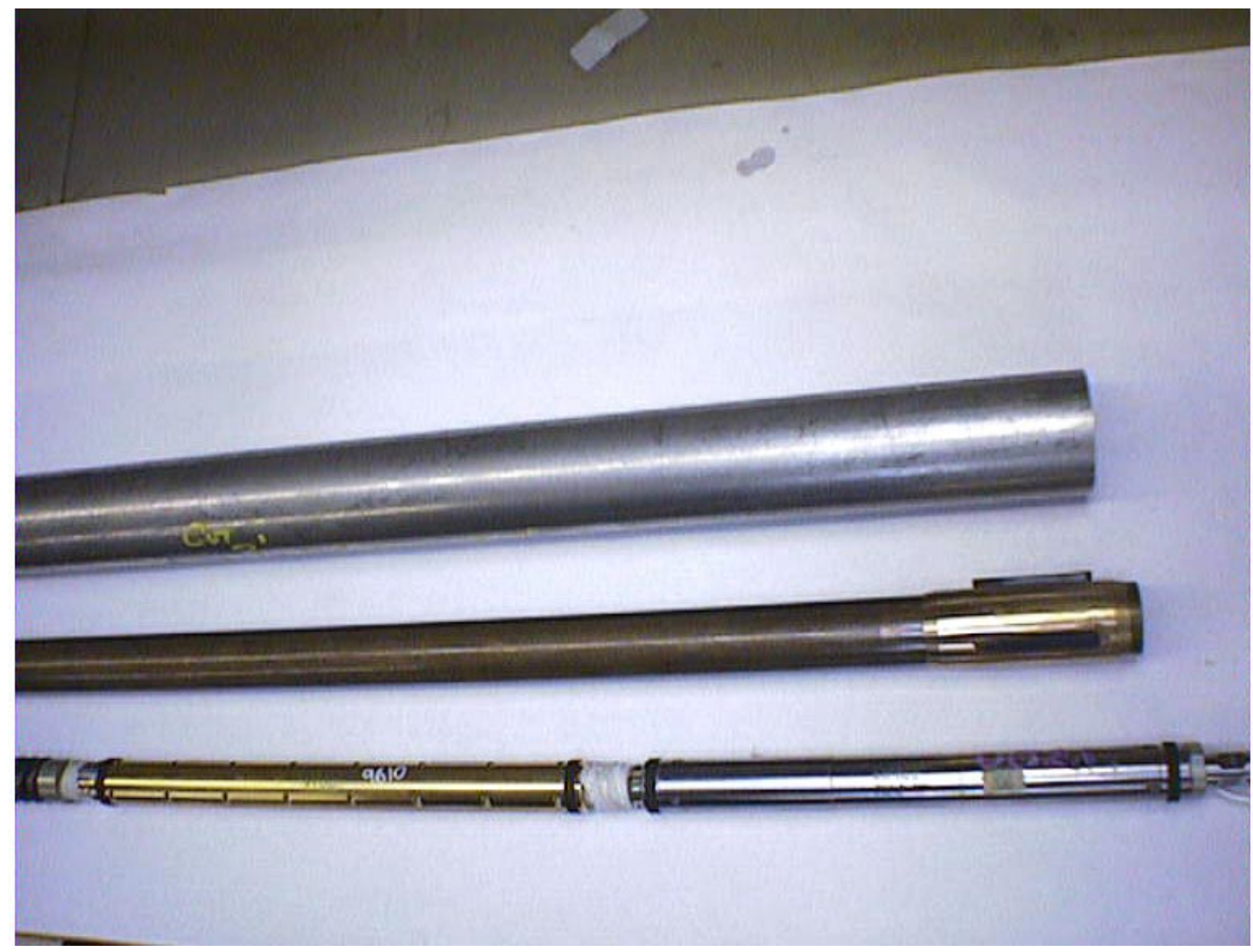

Figure 1: Gamma-ray module, pressure housing, and collar 


\section{Equipment and Procedure}

The test apparatus consisted of:

- A UGRM Gamma Ray assembly with software version Vpr16v8.hex. located in a 36-in $(91.44-\mathrm{cm})$ long pressure housing and collar, brought by Anadrill. The pressure housing was centralized in a standard 2.875-in $(7.30-\mathrm{cm})$ diameter collar, using two rubber centralizers.

- A UGRM scope software and laptop computer, brought by Anadrill

- A 34 milliCurie (mCi) Cobalt-60 source, provided by LLNL-Nevada

- A hand-held Geiger Müller survey instrument (Ludlum 14C3), provided by LLNL-Nevada

The VIPER gamma-ray package was placed on the ground just outside of the west door to building 600. The area was roped off to keep personnel away during testing. A hand-held Geiger Müller detector was located just behind the VIPER collar to monitor the radiation levels throughout the test. It was positioned to minimize potential shielding from the VIPER collar. Background counts were recorded by both detectors before and after the test.

The Cobalt-60 source was positioned such that it could be brought progressively closer to the detectors, at two-foot $(61 \mathrm{~cm})$ increments. The source was moved repeatedly closer until the VIPER detector reached its maximum of $65,000 \mathrm{cps}$. The first reading was done at 28 feet $(8.54 \mathrm{~m})$.

\section{Results}

Measurements were taken from the VIPER detector (counts/sec) and a Geiger Müeller hand-held detector (milliRoentgen/hr). The distance to the source measured in feet and background counts from both detectors were also recorded. The results are listed in Table 1, and plotted in Figure 2.

Table 1 - Recorded calibration results

\begin{tabular}{|l|l|l|}
\hline $\begin{array}{l}\text { Distance to source } \\
\text { (feet) }\end{array}$ & $\begin{array}{l}\text { VIPER reading } \\
(\mathbf{c p s})\end{array}$ & $\begin{array}{l}\text { Detector reading } \\
(\mathbf{m R} / \mathbf{h r})\end{array}$ \\
\hline Background reading & 60 & .05 \\
\hline 28 & 3,730 & 1.1 \\
\hline 26 & 4,360 & 1.3 \\
\hline 24 & 5,200 & 1.5 \\
\hline 22 & 6,220 & 1.7 \\
\hline 20 & 7,700 & 2.0 \\
\hline 18 & 9,650 & 2.5 \\
\hline 16 & 12,200 & 3.1 \\
\hline 14 & 16,310 & 3.9 \\
\hline 12 & 19,390 & 5.0 \\
\hline 10 & 32,800 & 7.0 \\
\hline 8 & 51,000 & 11.5 \\
\hline 7 & 61,350 & 14.7 \\
\hline 6 & 64,000 & 19 \\
\hline 12 & 22,250 & 5.0 \\
\hline 20 & 7,740 & 1.8 \\
\hline 28 & 3,700 & 1.1 \\
\hline Background reading & 59 & .05 \\
\hline
\end{tabular}

Note: 1 API $=1.3$ counts per second for VIPER in air. The API value is based on lower energy gamma-rays like those from Potassium, Thorium and Uranium 


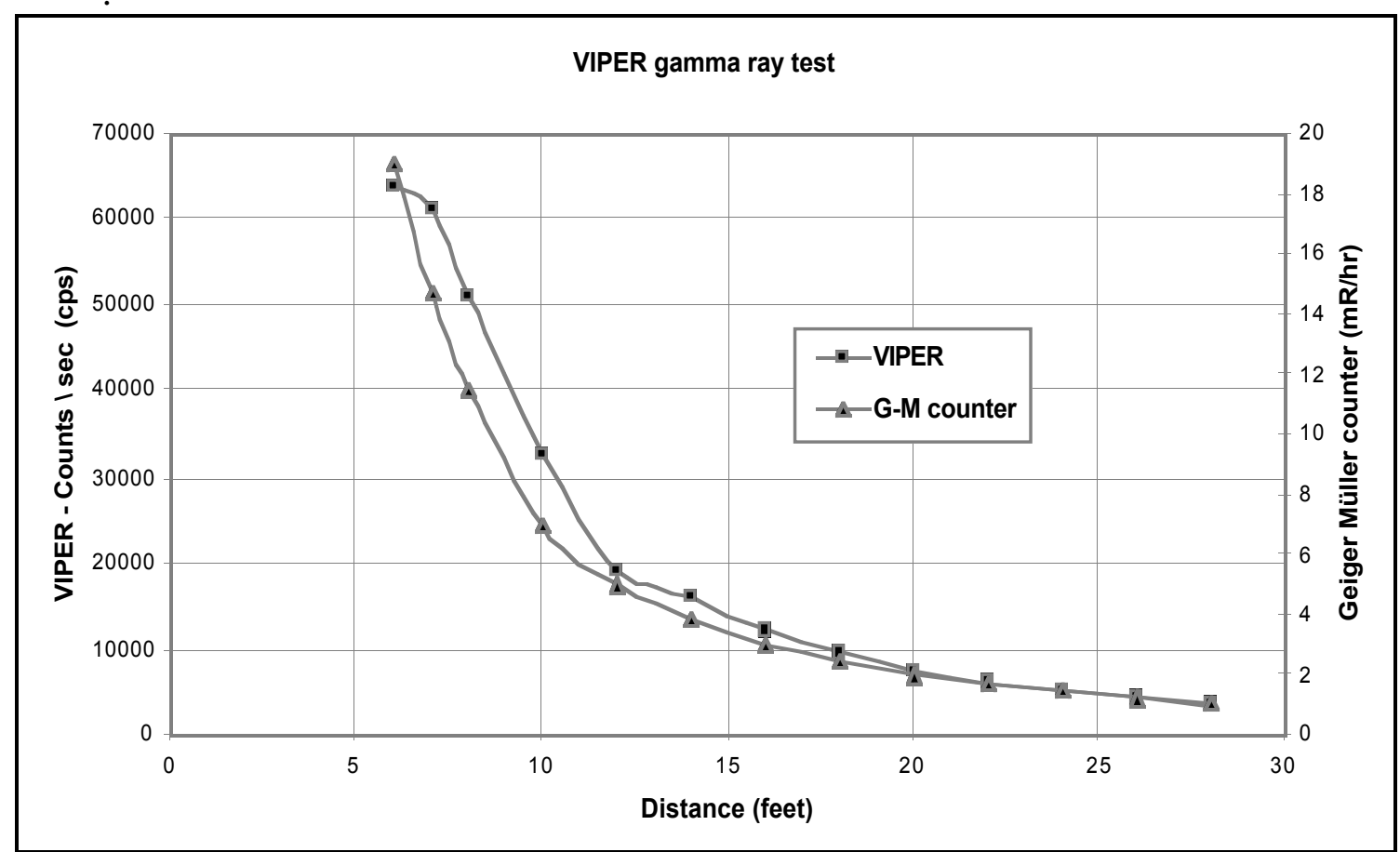

Figure 2 - Comparison of Measurements from the VIPER detector and the Geiger counter, as a function of distance.

A secondary test was completed for information purposes only. A 4.0-inch $(10.16$-cm) diameter steel pipe was installed over the VIPER collar to measure the effects of shielding on the detector. The wall thickness of the pipe was 0.5 in $(1.27 \mathrm{~cm})$. See Table 2 for results.

Table 2 - Measurements with a 4" OD x 0.5 " wall steel tube over the VIPER collar

\begin{tabular}{|l|l|l|}
\hline $\begin{array}{l}\text { Distance to source } \\
\text { (feet) }\end{array}$ & $\begin{array}{l}\text { VIPER reading } \\
\text { (cps) }\end{array}$ & $\begin{array}{l}\text { Detector reading } \\
(\mathbf{m R / h r})\end{array}$ \\
\hline Background reading & 44 & .05 \\
\hline 12 & 18,410 & 4.8 \\
\hline 10 & 27,200 & 7.5 \\
\hline 8 & 43,700 & 11.5 \\
\hline
\end{tabular}

\section{Conclusions from the Tests at NTS}

It can be seen that the relationship between the hand-held survey instrument and the VIPER detector is fairly consistent throughout the test. The data start to separate when the source is moved closer than about 12 feet $(3.66 \mathrm{~m})$ from the detectors. This variation can be accounted for by the test setup and the inherent differences between the detectors.

Test setup variation:

- The VIPER package was sitting on the ground, 1.5 in $(3.81 \mathrm{~cm})$ to centerline, whereas the handheld detector was 5 to 6 in $(12.7$ to $15.24 \mathrm{~cm})$ in the air. 
- The hand-held survey instrument was three to four inches $(7.62$ to $10.16 \mathrm{~cm})$ further back than the VIPER detector. Since the radiation detected decreases based on the distance squared, the handheld detector would tend to read lower than it should, especially as this distance becomes a larger percentage of the total.

Detector Package Differences:

- The detector in VIPER is a six-inch $(15.24 \mathrm{~cm})$ long NaI crystal, whereas the hand-held Geiger Müller instrument uses a much smaller detector.

- The hand-held Geiger Müeller detector used is well suited for detecting high-energy gamma radiation. Its performance at lower energy produces count rates up to 3 times higher than its operation at the high-energy levels. The Cobalt-60 source has very defined peaks with very little scatter in the higher energy levels.

Overall, the VIPER gamma ray package performed up to specifications without any problems.

A note on the secondary test: this test was done to confirm whether or not more metal around the gamma ray detector would allow the sensor to operate a higher gamma-ray levels. This was found not to be the case. Based on in-house data within Schlumberger, the 4-in $(10.16-\mathrm{cm})$ pipe should have reduced the counts by a factor of two. What was seen was a reduction of only 5 to $17 \%$. Steel has little effect on the high energy levels of Cobalt-60. The normal operating environments for VIPER are at much lower energy levels and subsequently more affected by steel shielding.

\section{SUMMARY}

Testing completed at NTS confirmed that the Anadrill gamma-ray tool was fully operational up to 50,000 API, as specified in the initial objective. Recorded results were within expected ranges when compared to the hand-held detector.

The gamma-ray module will require special "high-rate" detection software to be loaded prior to drilling operations. The other components within the VIPER system have been modified to operate with either software (normal or "high-rate") installed in the gamma-ray module.

The successful completion of this test is but one step towards the main goal. The next step will be testing this module in the VIPER tool during an actual "re-entry" drilling operation, which could be performed at NTS on a former U.S.event.

\section{REFERENCES}

Heuze, F.E. (1995),"Slimhole Drilling and Directional Drilling for On-Site Inspections Under a Comprehensive Test Ban - An Initial Assessment -", Lawrence Livermore National Laboratory, UCRL-ID-121295, 12p., July.

Maurer, W.C., Deskins, W.G., McDonald, W.J., Cohen, J.H., Heuze, F.E., and Butler, M.W., (1996), "Rapid Deployment Drilling System for On-Site Inspections Under a Comprehensive Test Ban - Preliminary Engineering Design -", Lawrence Livermore National Laboratory , UCRL-CR$\underline{125259}$, 55p., September. 


\section{ACKNOWLEDGMENTS}

This work was funded under contract W-7405-ENG-48 with the U.S. Department of Energy, for the DOE's Division of Nonproliferation and National Security.

We are thankful for the useful discussions with our LLNL colleagues D. Felske, and A. Friensehner, and for the participation of J. Haeberlin from LLNL and P. Kelly from Anadrill in the VIPER calibration at NTS.

The CTBT Program Leader at LLNL is J. Zucca. 


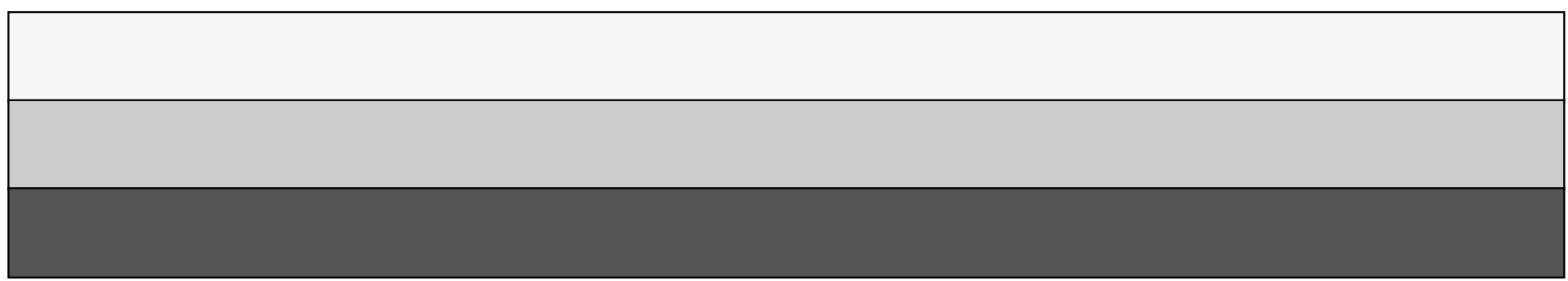

